nounced unequivocally in favor of making every effort to prevent the pollution of streams and, as far as possible, to keep all impurities from entering them. viz.: Minnesota, Wisconsin, 'Vermont, Kentucky, Delaware, New York, Province of Ontario, Missouri, North Carolina, Maryland, Province of Quebec. In all eleven.

The secretaries of the following named Boards doubt the feasibility or possibility of preventing pollution to a very considerable extent, and therefore declare in favor of permitting streams to be used freely and unrestrictedly as sewers, and looking elsewhere for drinking water, viz.: Alabama, Florida, Louisiana, Oklahoma Territory, Rhode Island, South Carolina. In all six.

The secretaries of the following named State Boards considered that the question could not be answered categorically, but that each case of pollution or threatened pollution should be decided upon its merits as it arises: Massachusetts, California, Illinois, Connecticut, Michigan, West Virginia, New Jersey. In all seven.

In reply to question No. 7. "If you favor the former alternative, do you consider it expedient, in view of the fact that so many of our streams pass from one State into another, to petition Congress for the passage of a law forbidding the pollution of streams throughout the entire country, and establishing a Rivers Conservancy Commission for the purpose of enforcing such a law?"

The Secretaries of the following State Boards express themselves as in favor of National legislation forbidding the pollution of streams and establishing a Rivers Conservancy Commission for the purpose of enforcing such legislation: Louisiana, Delaware, Province of Ontario, Missouri, Maryland, South Carolina, Illinois, Connecticut, Michigan, West Virginia, Wisconsin, Vermont, Kentucky, Province of Quebec. In all fourteen.

Dr. N. D. Baker, of West Virginia, says: "I would join in earnestly urging the above action upon Congress."

Dr. F. W. Reilly, of Illinois, says: "The proposition to secure a Rivers Conservancy Commission,with power, authority and means to determine individual cases on the basis of individual conditions has my hearty endorsement."

Dr. C. W. Chancellor, of Maryland, says: "I am decidedly in favor of a 'Rivers Conservancy Commission' with strong laws to prevent pollution of any water-way. The general government will be forced at an early period to enact a law to protect the water supply of Washington City, which is already greatly polluted by the States of West Virginia, Virginia and Maryland. Congress alone can remedy the evil."

Dr. R. C. Atkinson, of Missouri, says: "I heartily approve of such a measure."

Dr. P. H. Bryce, of Toronto, says: "I think the suggestion that the question of the pollution of streams be taken up as a Congressional matter should be approved of and urged by all interested in State or international sanitation."

Mr. E. B. Frazer, of Delaware, says: "I heartily approve of the above. Protect the streams, keep them as the Almighty made them."

The secretaries of the following State Boards are decidedly opposed to invoking the authority of Congress, believing that the separate States are fully capable of dealing with this problem: Rhode Island,
Florida, Massachusetts, New Jersey, Minnesota, California.

It will thus be seen that the consensus of opinion of practical sanitarians is strol gly in favor of legislative interference for the protection of the purity of water-supplies and streams; that in several States such opinion has crystallized into a public sentiment of such force as to compel the unwilling acquiescence of legislators and lead to the passage of laws for the purpose; that as an ideal question all regard it favorably; but that, as a practical question, the varying conditions of the several States modify the opinions of those residing therein. In some instances the drainage problems of the country are such as to make it appear almost an impossibility to prevent the pollution of streams; in others the manufacturing interests are paramount to all other considerations; and in a third class, the country is so sparsely peopled and there is such an entire absence of manufacturing industries, that the question is not with them an urgent one. Wherever it has forced itself upon the attention of sanitarians, and the difficulties are not so great as to make them appear at first sight insurmountable, but one opinion has been entertained and expressed. This being the case, is it not desiraable that this Section should formulate a request to Congress to appoint a committee to consider the expediency of the establishment of a "National Rivers Conservancy Commission," and transmit the same to the Association with a recommendation for its adoption?

In coming to a decision on this really momentous question, it is in the highest degree desirable that we should allow hygienic considerations and the interests of human life alone to have weight! Shall we permit local jealousies or inherited prejudices or questions of political organization to influence us? Are not thinking men who reside in large cities beginning to wake up to the fact that so far as municipal government is concerned we have been grasping at the shadow of liberty only to lose the substance? Shall we allow the bogy of centralization of power to deter us from advocating a measure which may prove the salvation of thousands of lives?

\section{THE NEED OF NATIONAL LEGISLATION FOR THE PROTECTION OF HUMAN LIFE.}

Read in the Section of State Medicine, at the Forty-third Annual Meeting of the American Iedical Association, held at Detroit, Mich.. June. 1892 .

BY A. N. BELI, A.M., M.D. oF BRookisx, $x$.

The need of national legislation for the protection of human life is based upon the knowledge of the transmissibility of epidemic diseases by commerce.

This need obtains to a larger degree for the United States than for any other country in the world, because while the States severally have many inherent rights and obligations of their own, and among those rights certainly that of self-protection against dangers to human life, the nation alone has the power to regulate commerce; and because, related to this commerce, the United States greatly exceeds any other country in the world as the collective centre of all nationalities and habits of life, more or less at variance with the conditions promotive of or in conflict with their own health or of the public health in this country. 
Commerce, as hitherto conducted in the United States, in default of national legislation to prohibit the introduction of epidemic diseases has been and is in constant antagonism to the efforts of the States and their seaports to prevent their introduction. Hence, it may be truthfully asserted with regard to sanitary progress in this country, that it has not only been made for the most part without the aid of the general Government, but in actual contention against the Government practice in the contrary direction.

At the outset the general Government essayed to aid the seaports by providing hospitals for those sick with infectious diseases, and warehouses for infected merchandise, both of which commodities it has persistently supplied to the jeopardy of the public health and at great pecuniary cost to the people. It has fallen under my own observation that some such structures eventually became so dangerous that the people in their vicinity destroyed them; but some still exist at other seaports, memorials of the nation's efforts to coördinate the introduction of pestilential diseases with an unrestricted commerce in them. Fortunately, every State in the Union has the power to impose regulations for its own protection; and all-or as many of the States as may so agreehave the power to impose interstate regulations for mutual protection against the introduction and spread of epidemic diseases in their midst. Indeed, not only every State, but every municipality and corporate village or town, has similar power; and it has been in the exercise of such power by the corporate communities and the States severally, that, excepting the progress made in army and naval hygiene, and the work of the National Board of Health during its brief existence, all the progress in preventive medicine in this country has been made by the people in their own behalf against the fostering of disease by commerce. For this reason it is that there are not wanting some advocates of State and local sanitation exclusively as abundantly sufficient. And they would sustain the proposition by reference to the triumphs over preventable diseases by a large number of local boards of health throughout the country, particularly to the progress made under the auspices of the state Boards. Indeed, such advocates-looking at but one side of the question-might cite one of the most triumphant examples of sanitary progress on record to show the sufficiency of local effort alone when fully aroused.

It has been a favorite maxim with me for many years that progress in measures for the protection of human life primarily consists in exposing the consequences of their neglect. In 1864, six years before the first State Board of Health (that of Massachusetts in 1869) was established, I was privileged to belong to a voluntary association of citizens in New York, ${ }^{1}$ whose members all appeared to me to be animated by the same sentiment-to seek out and publish the localizing causes of disease throughout the city. The report of the Association at the end of that year showed that, in an estimated population of $700,000,495,592$ persons lived in tenement-houses and cellars, with an average of seven and one-sixth families to each tenement-house, and that many took boarders besides. The tenement-houses of one of the most thickly populated districts contained from 10 to 50 families each. The pro rata of ground area to each occupant was less than 15 square feet, and

\footnotetext{
1 Citizens' Association.
}

the space in the apartments to each occupant less than 300 cubic feet. One half of the tenement-house population had less than 500 cubic feet of air space to each person. The filthy surroundings were loathsame in the extreme.

The total number of deaths reported for the year 1863 was 25,196 - an increase of 3,952 upon the previous year; during the year 1864 there were several hundred more, and for the whole population a fraction less than one death annually to every 35 of the living.

For a period of 25 years, terminating at that time, the number of deaths reported by the City Inspector annually had fluctuated from one death to every 39 to one for every 27, and had even been as high as one to every $22 \frac{1}{2}$ of the whole population; while among the most overcrowded tenement-house population it was one to every 19 of the living.

The outcome of that exposure was the establishment of the Metropolitan Board, in 1866. Under it and its subsequent modifications, cellar tenements have long since ceased to exist; the air space of the tenement-houses has been enlarged, by law, to not less than 600 cubic feet for each occupant; the deathrate of the city has been reduced to an average of about 24.5 per 1000 of the whole population; and for the tenement-house population-counting in the advantage gained by an improved class of tenementhouses-the mortality has been less than among the non-tenement class, due, doubtless, to the better surveillance of the tenement-houses by the Health Department. On the whole, a reduction of about 10 per 1000 of the population annually has been made in New York City since the establishment of the first scientific Board of Health there in 1866. The result since that time, as compared with a like period preceding the awakening of public attention and subsequent legislative action-brought about by the Citizens' Association-has been the saving of more than 500,000 human lives.

Again, the quarantine at the port of New York, aided (?) in the manner before indicated, and fed by commerce, had been, like the tenement-houses of the city,getting more and more deadly-proportional with patronage-until, in 1856 , it reached a climacteric period.

The Health Officer's residence was at Tompkinsville, and the boarding place and anchorage in the Narrows, between Staten Island and the Long Island shore. In this narrow channel, from opposite the northern end of Staten Island, extending southward, and including Gravesend Bay, between Coney Island and Fort Hamilton, in the immediate trend of the prevailing southwest wind toward the Long Island shore, not more than 300 yards distant, there were anchored at one time during that summer over 200 infected vessels, chiefly with yellow-fever. That the disease should have been communicated to the people in such proximity on the Long Island shore is perfectly consistent with the nature of such a mass of infected material everywhere. Moreover, it was through the midst of this accumulation of infected commerce that all vessels to and from the port of New York, for the time, had to pass.

But it was a blessed epidemic. It roused the people round about to the assertion of their rights, for which they did not cease to contend until the quarantine, as it was at that time conducted, was destroyed, and subsequently, by Act of the Legislature 
supplanted by the most efficient quarantine establishment in the world.

It would be an easy matter to cite other scarcely less signal triumphs of sanitation in the United States, independent of the several govermments, equal to any that have taken place elsewhere during the now more than forty years since $I$ have been not an wholly inactive observer. It is with knowledge limited to such progress in sanitation by the States and smaller communities that there are not wanting some men of influence wholly opposed to national legislation for the protection of human life. If the States and many populous communities severally have such power and have used it with such good results as those lllustrated by the examples cited, they ask, In what consists the necessity for national legislation?

First, because there is too much independent power on the part of State and municipal officials, and, above all, of merchants and their ship masters, to do as they please, regardless of sanitary knowledge, or to ignore its importance when its exercise does not happen to harmonize with the political standard set up, or to chime in with money-getting propensities at the risk of the public health.

Of these, examples are by no means wanting. As one on a small scale, but exceedingly mischievous in its direction, the port of Perth Amboy, N. J., has been a thorn in the side of the New York quarantine and a menace to the health of the city ever since it became a port of entry. It claims the right-though not in so many words-and has frequently made attempts to exercise it (and not always ineffectually, there is reason to believe), to exercise its privilege as a port of entry for infected vessels whose masters desire to shun the New York quarantine, and issuing a new clearance to New York, under the privilege of being a healthful port and a pur-blind health officer to the condition of the vessel.

But dangerous as such powers are, independent of even State control, they are insignificant as compared with some officials in higher places who would sacrifice the health of the State and nation to the opportunity for embarrassing a political opponent.

Every sanitarian in the Union knows that we have not far to seek for a prominent example in justification of these remarks; that for several years preceding the arrival of cholera infected vessels at the port of New York in 1876 the quarantine establishment of New York had been allowed to decay and become notoriously deficient in means for the protection of the public health-in the face of universal intelligence that cholera was aboard-because the Governor of the State preferred to take the risk of a cholera epidemic rather than approve of legislative appropriations for preventive measures to be applied by those who differed with him in politics.

Unfortunately, this is not an isolated case, only in so far as it is the less excusable by reason of the prominence of the official and the consequently increased danger of a following. Indeed, this is already manifest by the action of his immediate successor, who has, for professedly economic reasons, just vetoed an appropriation for completing the repairs which his predecessor was driven to undertake by Mayor Hewitt and others of New York, when the amount asked for by the quarantine commissioners to complete the work would have increased the State tax per capita only the sixth of one cent. The func- tions of the Health Officer of the port of New York, as with that of every other port health officer in the United States, end with each case as it arises, while the recurrence of cases is continuous, a constant tax upon the port and the State, a menace to the public health, and an unmitigated burden to commerce.

Twenty-eight years ago, at the meeting of this Association, at Boston, in 1865 , I submitted a brief paper on the Introduction of Disease by Commerce. We have learned a good deal about the etiology of some commercial diseases since that time, but nothing to gainsay the force of the illustration there given, particularly with regard to yellow-fever, which is a constant menace to the southern section of our country, or of the pertinence of other infectious diseases introduced by commerce.

But that paper was evidently premature. And for that reason, fortified as it now is by increased observation and more general knowledge on the subject, an abstract of it is deemed appropriate to this occasion, as follows:

"Since yellow-fever appeared in the Brazils, about sixteen years ago" (it has now been forty-four), "it has extended over the entire Gulf of Mexico, the West Indies, and to most of the Southern States, and finally to the Pacific Coast. But all the while it has clung with tenacity to regions and localities remarkable for general resemblance -for the time being, at least-in local and climatological conditions.

"In 1851-52 the harbor of Rio Janeiro was crowded with infected vessels, many of them destined for the Pacific. How many of them arrived there still infected, and touched at places where yellow-fever soon after for the first time prevailed, we have no means of knowing. But a few have been traced.

"About the middle of the year 1851 the steamer New World, on her way to California, having touched at Callao after having lost almost her whole crew by jellow-fever in Rio, The steamer Quito also, during the same season, lost several of her crew there, proceeded to the Pacific, and arrived at Callao in April, 1852. Soon thereafter a mild form of fever broke out in Lima and along the coast of Peru, which the natives called 'pelusa,' just as in 1849 the precursory form of fever which prevailed in Rio was called "polka.' The disease speedily developed into a perfect type of yellowfever, and has become domiciled.

"June 6, 1865, the steamer Ben Franklin arrived at Norfolk, Va., from St. Thomas, where she had lain several months during the prevalence of yellow-fever, and had lost several of her crew with the disease, and had also lost two or three more with it on the voyage to Norfolk: but at the time of her arrival she had no one on board sick with it. On July 5, a man, who had been working on the boiler of the Ben Franklin two days before, was taken with yellow-fever, and died on the fourth day of the disease. This was the starting point of the fever, which subsequently prevailed so extensively at Portsmouth and Norfolk until the beginning of cold weather.

"Early in December, 1857, the U. S. Steamer Susquehanna arrived at San Juan de Nicaragua from the Mediterranean two months before, touching by the way at Genoa, Madeira and Key West. She remained at San Juan until the first of the following April, having had during the whole time she laid there a constantly increasing sick list of a precursory fever. At first intermittent, then remittent, but all recovering until March 20 , when a case became malignant and died.

"The ship put to sea April 1, and on the 5th arrived off Port Royal, Jamaica, with 106 officers and men down with yellow-fever. Most of these were sent to the hospital, and on the third day afterward the ship sailed for New York, where she arrived April 15, with 51 on the sick list."

The remarkable feature in the case of the Susquehanna was that, at San Juan, where the yellow-fever first broke out on board, there was no yellow-fever at that place, and the disease had never been known to occur there. Moreover, the Susquehanna had been more than two years on service in the Mediterranean 
without having had any extraordinary sickness on board when she was ordered to San Juan de Nicaragua; but she had had yellow-fever on board during her preceding cruise in the Gulf Squadron the summer before she was ordered to the Mediterranean, three years before. She was supposed to have been cleansed before she was so ordered; and owing to the unpredisposing conditions of the climate during the interval and while she remained on the Mediterranean station, to the revival of the yellow-fever infection, which, as the sequel shows, she still retained until she returned to the conditions of the yellowfever habitat at the port of San Juan de Nicaragua.

It is contended by those who persist in their endeavors to elude every restriction upon commerce in disease by foul vessels, that there have been such improvements in ship architecture during recent years as to have well-nigh overcome such conditions as those cited. They would have us believe that because the modern iron ships and water ballast, which have taken the place of wood and stone, are more easily kept clean, they are less liable to infection than the ships of a past generation. But the continued and more certain propagation of epidemic diseases by commerce, and by emigrant ships particularly, is conclusive testimony against that contention. Indeed, admitting the improvements with regard to the passenger-carrying capacity of emigrant ships, such improvements are not infrequently found to be very decidedly in conflict with the health of the passengers, and no less dangerous to ports of arrival than were the passenger and traffic vessels of a past generation.

All sanitarians are more or less familiar with the conditions promotive of disease comprised within the tenement walls of brick vertically and longitudinally divided into compartments by hallways and partitions, pierced here and there with doors for ingress and egress, and provided with windows for light and some fresh air-by shaft or otherwisefrom pavement to roof, though ever so much overcrowded. And in civilized communities everywhere the misery of people who, through poverty or other causes, occupy such unhealthful tenements, has never failed to excite public sympathy; insomuch, indeed, that in some communities, in Glasgow, for example, whole blocks of such tenements have been destroyed by national law and healthful tenements substituted, with the result of reducing the deathrate among those who occupied them from 70 to 24 per 1,000 .

But not so by any means with regard to the iron tenements afloat, with their several submerged floors and apartments-a basement twenty feet below the water level, with a filthy, stagnant sewer of bilge water beneath it, without a window for light or air nearer than thirty feet above the sewer, and no opening for egress or ingress except through the roof-deck, and this deck not infrequently converted into a pound for cattle. The intervening deck between the cattle pen and the steerage for emigrants is commonly divided into compartments for the mails and storage. The required air space in the steerage by $\mathrm{law}^{3}$ is from 100 to 120 cubic feet per capita.

Below the steerage is the hold for cargo, dark and airless, except by the ekeage of the foul gases into it from the bilge, which contributes more or less foul-

2 English Acts of Parllament, 1866-71,

3 Acts of Congress, 1882 and 1887. ness to the cargo according to the tightness or otherwise of the ship's lining between and the nature of cargo.

Surely it is no wonder that such tenements afloat, with no sanitary surveillance worthy of the name, should become the hatcheries of typhus-fever and other infectious and communicable diseases. The Massilia, by which typhus-fever was introduced into New York in January last, is an example.

Five years ago, at the meeting of this Association in Chicago, I made a report on "Medical and Sanitary Service on Board Immigrant Passenger Vessels," containing a computation of the death-rate of 27,157 emigrants who took passage to New York during the month of April, 1887. Forty-one died on the voyage -an annual rate of over 55 per 1,000 , giving ten days as the average duration of the time the passengers. were on board ship. The mortality was not particularly excessive for that month, and it is not believed to be in excess of the present rate.

It is the misfortune of the New York quarantine that no record of the history of infected vessels has been kept; the health officers seem to have regarded their records as personal property, and have taken them away with them. Indeed, in their published official reports even the names of infected vessels are rarely given except incidentally. The report for 1891 is an exception-at least with regard to emigrant ships. But gleaning such records as I have. been able to obtain, covering the last five years, there is no difficulty in designating some of the emigrant ships as rounders with regard to their liability to infectious diseases, indicating a continuous state of receptivity. The Alesia, which brought cholera to quarantine in 1887, is an example. She brought small-pox twice in 1888, twice in 1890, and she has recently arrived with measles. There are severa]. other repeaters within the same period, of two or three times each. And Dr. William M. Smith, who has occupied the post for nearly twelve yearsrecently relieved-informs me with regard to yellowfever particularly, his recollection is that the disease was remarkably persistent year after year to certain vessels during the early years of his service. His: report for 1889 contains this remarkable statement: The fact is worthy of special consideration, as illustrating the efficiency of the system adopted at this quarantine for an exclusion of yellow fever, that in no instance has the disease occurred among the passengers or crew of vessels from ports known to be infected ports; the cases that have arrived were from localities where the disease was not known to exist, and on vessels that carried clean bills of health.

It would be difficult to adduce clearer evidence than this of the persistence of ship infection and its danger, even when not directly from infected ports.

That such infected conditions of merchant vessels are no less common now than they were thirty years ago, it is only necessary to call attention to the outbreaks of yellow-fever continually occurring on board vessels in frequent communication with Rio, Santos, Guayaquil, and other yellow fever ports, in commercial intercourse with the seaports of the United States.

What is said with regard to the persistence of the yellow-fever infection in such vessels also applies to other infections and the recurring outbreaks of infectious disease on board emigrant ships-they are not disinfected.

My opinion, with regard to efficient disinfection 
and the means of applying it, is sufficiently wellknown to require no repetition in this place. It will suffice to state that while steam is everywhere acknowledged to be the most efficient of all means, it is still, so far as I am informed, unused for the disinfection of vessels at our quarantine stations. At the New York establishment it has been used twice-first to the U.S. transport steamship Delaware, infected with yellow-fever in 1862; and second, to the emigrant steamship Britannia, infected with cholera in 1887 -in both instances in accordance with my advice, and with complete success.

Moreover, from all I have been able to Jearn of common practice in the premises, no attempt is made to apply such disinfectants as are used to the bilgethe breeding place of infective germs-and but rarely the hold. The masters of infected emigrant ships have been directed, after permission to go to the wharves of the city and removing cargo, to disinfect the hold with sulphur or chlorine, and to wash with mercuric-bichloride solution; but I have not been able to find any one who has seen this done-even if it ever has been done. Is there any one who appreciates the by no means overwrought description I have attempted to give of a modern emigrant ship, who thinks that the dark and close recesses and crevices more or less common to all vessels, the special lurking places of disease germs, are ever penetrated by such means; or that the filthy paste composted by the motions of the ship, of the leakage at yellow-fever ports and bilge water with which the limbers of vessels are plastered from the keelson to the deck are ever reached by the bichloride or any other solution, or by any fumes evolved in the hold, without exposing the limbers?

But I am gratified at being able to state that Dr. Wm. T. Jenkins, the recently appointed Health Offcer at the port of New York, promises the speedy application of steam to infected vessels, by which means, at a sufficlent temperature to kill all disease germs without injury to the vessel, disinfection may be effectually accomplished.

While the recent laws of France and Germany against the importation of American pork obtained, no American ship laden with pork was cleared for those comntries. Would it be a greater burden on France or Germany to prohibit the exportation of typhus or any other like dangerous disease thence to the United States than was the prohibition of pork from America? The solution of the question requires no argument, and it applies equally to all other countries.

The port health officers of the United States, and the Health officer of the port of New York in particular, with regard to emigrant ships, are our sole reliance; they are assumed to possess ample power for the prevention of the introduction of epidemic diseases from abroad. But so long as emigrant ships are permitted to receive passengers and their luggage without restriction; vessels known to be infected with cholera, or to have merchandise suspected of cholera infection, refused entry at English ports, but given "clean" bills of health to proceed to American ports; merchant ships to receive any sort of merchandise at the tropical ports of South America and the West Indies where yellow-fever obtains, and clear for American ports without credible bills of health-so long as any of these conditions obtain, and so long as there is no intel'igent and reliable sanitary inspection at the ports of departure, and for emigrant ships, no competent sanitary supervision during the voyage, just so long will the people of the United States be subject to epidemics imported from abroad.

Every person acquainted with the construction of sea-going vessels, and with knowledge of the practices of those who command them, knows that it is often wholly impracticable, under the wilful deceptions that commonly obtain among the masters and medical officers of emigrant ships, and the clearance conditions of merchant vessels generally, for health officers to obtain reliable information with regard to infectious diseases at foreign ports; the sanitary condition of the vessels at the time of clearing; their previous condition-whether recently infected or not -or the nature of any diseases that may have occured during the voyage. Indeed, the present state of conducting commerce in epidemic diseases. by which they are so carefully concealed by those who set more value upon dollars than upon human life, is such that it is frequently altogether impracticable for the port health officer to discover their hiding places.

The only way of meeting and overcoming these dangerous conditions to the health of the people is by efficient international regulations, and a necessary prelude to these is a national health service-a service such as that contemplated by the bill of Senator Harris for a National Board of Health, introduced in the Senate, December 10, 1891.

As compared with other proposed national legislation with the same object in view:

It provides for a competent personnel in the organization of the Board; the utilization of the consular service of the United States as means of information; the Naval and Marine Hospital services ; coöperation with State and municipal authorities; voluntary public and private associations-in short, with all sources of information relating to climatic and other conditions affecting the public health. While it makes it unlawful for any merchant ship or vessel from any foreign port to clear for any port of the United States except under clearly defined regulations for the protection of the public health, it respects the right and obligations of foreign nations to practice sanitation at the ports of departure, andwith regard to emigrant ships particularly- during the voyage. It provides against such cases as the one cited-the action of the Health Officer of Perth Amboy against the quarantine regulations of New York. It offers aid to all sanitary authorities in the United States when required, to prevent the introduction, to seek out and destroy epidemic diseases and the conditions which promote them. There is no need of pursuing the excellent provisions of this bill in further detail. I prefer to take it for granted that every member of the Section has made himself familiar with it.

One important deficiency, however, is apparent. While it provides for and exacts practical sanitation by the rightful authorities at ports of departure of foreign nations, it exacts none at our own ports; it leaves the clearance of vessels, emigrant or otherwise, proved to be infected-as was the Massiliaat the discretion of those who command them. A clean bill of health can be obtained from the port in such cases in the absence of prevailing epidemic disease in the city, yet the ship may be dangerously foul. To fill the Bill, in this particular, the Government is 
already adequately equipped-it only needs detail. The United States Marine Hospital Service, has, in default of international legislation (contemplated by Senator Harris' bill), done some excellent work through the courtesy of foreign nations-particularly at the port of Havana-to prevent the transmission of epidemic diseases thither. And, apparently, with the purpose of continued reliance upon the service of its medical officers in foreign ports, by courtesy, a bill is now before Congress to that end. But surely it must be well known to all persons conversant with the exclusive rights and practice of foreign nations, that such sanitary service is essentially unstable, ever liable to conflict with the sanitary authorities at ports of departure, and cannot be relied upon to prohibit the departure of an infected ship. The Marine Hospital Service is out of its sphere in this direction, while there is an open field for its labors in another, if the United States would set the example by practicing its own precepts-would see to it that the condition of every vessel, before she is permitted to receive cargo, is clean in a sanitary sense, and not at the mere voice of her master.

Surely it would be difficult to designate a more inviting field of labor-certainly none more germane to all that pertains to the health of mariners-than this for the Marine Hospital Service.

With such coöperation as this suggestion contemplates, under the auspices of a national board of health as provided for in Senator Harris' bill, and the international sanitary service which it would then be certain to secure, the transmission of epidemic diseases by commerce would speedily cease.

PUBLIC BATHS A PREVENTIVE OF DISEASE.

Read in the Section of State Medicine at the Forty-third Annual Meeting of the American Medical Association, held at Detroit, Mich., June, 1892 .

BY CHARLES H. SHEPARD, M.D.,

OF BROOKXYN, NEW YORK.

A nation is powerful in proportion to the health of its people, and individuals are successful in life largely in proportion to their good health. Man begins existence with a certain stock of vitality, and his success or failure depends upon a careful or prodigal use of that capital, so that good health, which should be his birthright, is of more importance than special fitness for life work.

The losses to the community from disease are beyond estimate, yet these are so common as to blunt our realization of the conditions that surround us. What more desirable therefore, than to seek some measure of relief? It is well to be able to cure disease, but a thousand fold better to prevent it. Herein lies the physician's most noble field of work, that of Preventive Medicine.

Of all forms of prevention or cure, none appeals so directly to common sense as that of baths. None are more simple, and none more powerful when rightly directed. They are inexpensive, and easily put into practice. They act upon the whole surface of the body, and as a rule are agreeable to all; for by quickening the action of the skin a more vigorons action of every internal organ and function is secured.

There are baths of many kinds, the swimming bath, the plunge, shower, douche, warm water baths,medicated baths, mud baths, and the steam or Russian baths; lately the warm water shower bath has deservedly won much favor, but for completeness of adaptation to all classes and conditions of health and disease, no bath that ancient or modern science has yet devised, is equal to the hot air, or as it is more commonly called, the Turkish bath. It is a natural stimulus, and invigorates as nothing else can. It meets all the conditions, either local or general, where any bath is indicated, more fully than any other process.

It has accomplished more as a remedy than any other one agency, and has never been known to injure, when applied by competent hands.

The action of heat, which constitutes the main feature of the Turkish bath, increases the vigor of elimination, and gives full opportunity for the destruction of poisonous ptomaines which are quickly rendered inert or thrown out entirely. The secretions are made more active, and the excretions are increased in volume and efficiency. The increased circulation promotes the discharge of old or used up tissue and the building up of new. The blood is at once a food stream and a sewage stream; for the living body is in solution in the blood, as is also the dead body that has done its work and needs to be eliminated. When it is seen that rheumatism or any other blood disease, which is acknowledged to be of microbic origin, has been quickly relieved by the action of heat, as applied in the Turkish bath, what more logical than to consider that this effect is produced through the destructive action of heat upon the microbes? Furthermore, by purifying and invigorating the circulation, it is reasonable to suppose that the normal germicidal activity of the serum of the blood and other fluids of the body is increased. This throws a hopeful light upon the future treatment of disease. No matter how certainly we may recognize disease, or how quickly we may relieve the pains and penalties of an outraged nature, if we do not thereby learn to avoid the cause, we are pursuing only an ignis faturs, and the lesson of disease is lost.

The modern science of medicine made a great step forward when it came to the knowledge of the disease of the cells, otherwise called cellular pathology. Di ease seems to be the result of blood poisoning. Symptoms are but an effort of nature to dislodge this poison, or obtain freedom from it. It. is an interesting thought of Dr. Carpenter that cancer is an excretory organ, formed to get rid of poisons in the system. The organic matter given off from the lungs alone, and which is a deadly poison, has been estimated at thirty or forty grains a day for each adult. It is recognized that a drowned man is only a poisoned man, because the waste that is continually going on in every part of the system is of such deadly character as to destroy life in a few moments. When the eliminative functions are in any way interfered with, in so far must the man be poisoned. This is due to the formation and absorption of poisonous substances, and while the specific germ is a cause of disease, the chemical factor is even more important.

In the work of elimination, the depurative process through the skin, is equally, if not more important than that through the bowels and kidneys. Ordinary colds are best explained by the supposition that certain effete matters, which in health are normally excreted by the skin, are retained. This theory is borne out by the effects on the nervous system, 